\title{
Increased mRNA Levels of TCF7L2 and MYC of the Wnt Pathway in Tg-ArcSwe Mice and Alzheimer's Disease Brain
}

\author{
Elin S. Blom, ${ }^{1}$ Yijing Wang, ${ }^{1}$ Lena Skoglund, ${ }^{1}$ Anita C. Hansson, ${ }^{2}$ Massimo Ubaldi, ${ }^{3}$ \\ Anbarasu Lourdusamy, ${ }^{3}$ Wolfgang H. Sommer, ${ }^{2}$ Matthew Mielke, ${ }^{4}$ Bradley T. Hyman, ${ }^{4}$ \\ Markus Heilig, ${ }^{2}$ Lars Lannfelt, ${ }^{1}$ Lars N. G. Nilsson, ${ }^{1}$ and Martin Ingelsson ${ }^{1}$ \\ ${ }^{1}$ Section of Molecular Geriatrics, Department of Public Health and Caring Sciences, Uppsala University, 75185 Uppsala, Sweden \\ ${ }^{2}$ Laboratory of Clinical and Translational Studies, National Institute on Alcohol Abuse and Alcoholism, National Institute of Health, \\ Bethesda, MD 20892-1108, USA \\ ${ }^{3}$ Department of Experimental Medicine and Public Health, University of Camerino, 62032 Camerino, Italy \\ ${ }^{4}$ Massachusetts General Hospital, Harvard Medical School, Charlestown, Boston, MA 02119, USA \\ Correspondence should be addressed to Martin Ingelsson, martin.ingelsson@pubcare.uu.se
}

Received 27 October 2010; Accepted 24 November 2010

Academic Editor: Mikko Hiltunen

Copyright ( 2011 Elin S. Blom et al. This is an open access article distributed under the Creative Commons Attribution License, which permits unrestricted use, distribution, and reproduction in any medium, provided the original work is properly cited.

Several components in the Wnt pathway, including $\beta$-catenin and glycogen synthase kinase 3 beta, have been implied in $\mathrm{AD}$ pathogenesis. Here, mRNA brain levels from five-month-old tg-ArcSwe and nontransgenic mice were compared using Affymetrix microarray analysis. With surprisingly small overall changes, Wnt signaling was the most affected pathway with altered expression of nine genes in tg-ArcSwe mice. When analyzing mRNA levels of these genes in human brain, transcription factor 7-like 2 (TCF7L2) and v-myc myelocytomatosis viral oncogene homolog $(M Y C)$, were increased in Alzheimer's disease $(\mathrm{AD})(P<.05)$. Furthermore, no clear differences in TCF7L2 and MYC mRNA were found in brains with frontotemporal lobar degeneration, suggesting that altered regulation of these Wnt-related genes could be specific to AD. Finally, mRNA levels of three neurogenesis markers were analyzed. Increased mRNA levels of dihydropyrimidinase-like 3 were observed in AD brain, suggesting that altered Wnt pathway regulation may signify synaptic rearrangement or neurogenesis.

\section{Introduction}

Alzheimer's disease $(\mathrm{AD})$ is the most common form of dementia. The most prominent histopathological features of the $\mathrm{AD}$ brain are extracellular plaques, mainly containing amyloid- $\beta(\mathrm{A} \beta)$ peptides, and neurofibrillary tangles largely consisting of hyperphosphorylated tau. Studies on familial cases of $\mathrm{AD}$ have identified several disease-causing mutations in the genes for the amyloid- $\beta$ precursor protein $(A P P)$ [1] and for the presenilins (PSEN1 and PSEN2) [2, 3]. In addition, the $\varepsilon 4$ allele of the gene for apolipoprotein $\mathrm{E}$ $(A P O E)$ lowers the age at onset of sporadic late-onset $\mathrm{AD}$ in a dose-dependent manner $[4,5]$. All these genetic variants result in increased levels or in an altered aggregation of
$\mathrm{A} \beta$, indicating a central role of $\mathrm{A} \beta$ in the disease process. However, it is still unclear which downstream pathways that are causing the synaptic dysfunction and cognitive failure seen in $\mathrm{AD}$.

Gene expression studies have found a wide range of pathways that are altered in both human postmortem $\mathrm{AD}$ brains and transgenic mouse models of AD. Examples of such pathways include mitochondrial abnormalities, oxidative stress, inflammation, and calcium dyshomeostasis [6]. Moreover, the Wnt signaling pathway, consisting of a complex network of proteins, has been implicated in $\mathrm{AD}$ pathogenesis. For example, glycogen synthase kinase 3 beta (GSK3 $\beta$ ) hyperphosphorylates tau [7] and increases levels of $\beta$-catenin in PSEN1 transgenic mice [8]. During Wnt 
TABLE 1: Mouse samples studied.

\begin{tabular}{llcc}
\hline Type & $n$ & Age (weeks \pm SEM) & \% female \\
\hline Tg-ArcSwe & 6 & $20.5 \pm 1.5$ & 33 \\
Nontransgenic & 6 & $20.6 \pm 1.4$ & 67
\end{tabular}

Tg-ArcSwe: transgenic mice, Nontransgenic: nontransgenic littermates.

signaling, $\beta$-catenin translocates to the nucleus where it forms complexes with transcription factor LEF/TCF (lymphoid enhancer factor/T-cell factor) and activates target gene expression. Finally, the Wnt pathway is also involved in cell differentiation and cancer development [9].

Transgenic AD mice models have been of importance to the understanding of disease mechanisms. One of these models, the tg-ArcSwe mouse, overexpresses human APP with the Swedish and the Arctic mutation. Studies on tgArcSwe mice suggest that intraneuronal $A \beta$ aggregates, which appear at one month and increase with age before the onset of extracellular plaque deposition at six months $[10,11]$, may be responsible for the spatial learning deficits in these mice [12]. This mouse model would thus be suitable to study molecular changes related to early $\mathrm{A} \beta$ aggregation.

In this study we wanted to analyze and compare gene expression patterns between young tg-ArcSwe and nontransgenic mice. In addition, we aimed at investigating whether differentially expressed genes in this model also were altered in brains from $\mathrm{AD}$ patients.

\section{Materials and Methods}

2.1. Samples. Six tg-ArcSwe and six nontransgenic mice (littermates) were sacrificed by cervical dislocation. The brain stem, cerebellum, and olfactory bulb were removed by dissection, and the remaining hemispheres were frozen separately on dry ice and stored at $-80^{\circ} \mathrm{C}$ until processed. All mice were approximately five months old and were of the same genetic background, $\mathrm{C} 57 \mathrm{Bl} / 6 \mathrm{~J}$ (Table 1). The use of mice had been approved by the local ethical committee for research on laboratory animals.

Human brain tissue from the anterior part of temporal neocortex of $13 \mathrm{AD}$ cases and nine age-matched controls was obtained from the Alzheimer's Disease Research Center (ADRC) at Massachusetts General Hospital in Boston, USA (Table 2). In addition, a separate set of tissues from the anterior part of frontal neocortex from nine cases with frontotemporal lobar degeneration (FTLD) and nine agematched controls, also from ADRC, were included (Table 2). The tissues were stored at $-80^{\circ} \mathrm{C}$ until processed. This study was approved by the Regional Ethical Committees in Uppsala, Sweden, and Massachusetts General Hospital, Boston, USA.

2.2. RNA Extraction and cDNA Synthesis. Total RNA was extracted from both mouse and human brain tissues. The samples were homogenized in TRIzol (Invitrogen, Carlsbad, CA, USA), and total RNA was extracted according to the manufacturer's protocol. The total RNA was further purified using RNeasy Mini Kit (Qiagen, Valencia, CA, USA), following the manufacturer's protocol. Total RNA quantity was measured with NanoDrop ND-1000 UV-Vis Spectrophotometer (NanoDrop Technologies, Wilmington, DE, USA) and RNA integrity through the $28 \mathrm{~S}: 18 \mathrm{~S}$ rRNA ratio, as measured by the Agilent 2100 Bioanalyzer (Agilent Technologies, Palo Alto, CA, USA). First-strand cDNA synthesis was carried out on $2 \mu \mathrm{g}$ total RNA with Superscript II firststrand synthesis kit for RT-PCR (Invitrogen), according to the manufacturer's protocol. Finally, $2.5 \mathrm{ng}$ of cDNA was used for quantitative PCR (qPCR).

2.3. Microarray Analyses. Individual total RNA samples from tg-ArcSwe and nontransgenic mice were hybridized to Affymetrix GeneChip Mouse Genome 4302.0 arrays (Affymetrix, Santa Clara, CA, USA). Robust multichip average expression values were obtained from six arrays per group and further analyzed for differential expression. Using the Database for Annotation, Visualization and Integrated Discovery (DAVID) [13], differentially expressed genes with a $P$-value of less than .05 from the microarray analysis were classified into different molecular pathways according to the Kyoto Encyclopedia of Genes and Genomes (KEGG) [14]

2.4. Quantitative PCR. Levels of mRNA from selected genes were measured in mouse and human brain samples with qPCR using the SYBR green chemistry on the MyiQ Single Color Real Time PCR Detection System (Bio-Rad, Richmond, CA, USA). The samples were prepared in a volume of $25 \mu \mathrm{L}$, containing $2.5 \mathrm{ng}$ cDNA, 2x Power SYBR Green PCR Master Mix (Applied Biosystems, Foster City, CA, USA), and $200 \mathrm{nM}$ of each primer (sequences available upon request). Next, the mixture was denatured in $95^{\circ} \mathrm{C}(10 \mathrm{~min}$.), followed by 40 cycles at $95^{\circ} \mathrm{C}(15 \mathrm{sec}$. $)$ and $60^{\circ} \mathrm{C}(1 \mathrm{~min}$. $)$ before a final incubation at $95^{\circ} \mathrm{C}(1 \mathrm{~min}$.). All primers were designed to have an annealing temperature of $60^{\circ} \mathrm{C}$.

All samples were run in triplicates, including a calibrator sample. Wells without template were included as negative controls. Gene expression was determined relative to $G A P D H$ and normalized to the calibrator sample using the $2^{-\Delta \Delta \mathrm{Ct}}$ method (Applied Biosystems). Primers were designed using Primer Express Software (Applied Biosystems) or obtained from online Real Timer PCR Primer and Probe Database [15]. Primers were evaluated in a qPCR efficiency test on a dilution series of template. Unpaired $t$-tests with Welch correction were performed using GraphPad InStat (GraphPad Software, San Diego, CA, USA).

2.5. Western Blot on Human Brain Samples. For all subjects, human brain tissue samples from the same region as used for qPCR were homogenized in RIPA buffer $(50 \mathrm{mM}$ Tris ( $\mathrm{pH} 8.0$ ), 1\% NP-40, 0.5\% sodium deoxycholate, and $150 \mathrm{mM} \mathrm{NaCl}, 0.1 \%$ SDS) supplemented with Complete Protease Inhibitor Cocktail Tablet (Roche Applied Science, Indianapolis, IN, USA), $1000 \mu \mathrm{L}$ per $50 \mathrm{mg}$ tissue. The homogenate was incubated at $4^{\circ} \mathrm{C}$ for two hours under constant agitation. In the following, all incubation steps were at room temperature. 
TABLE 2: Human subjects studied.

\begin{tabular}{lccccc}
\hline Diagnosis & Area & $n$ & Age (years \pm SEM) & PMI (hours \pm SEM) & \% female \\
\hline AD & Temporal ctx & 13 & $79.8 \pm 1.5$ & $14.8 \pm 1.5$ & $19.9 \pm 3.9$ \\
C & Temporal ctx & 9 & $79.8 \pm 1.8$ & $12.9 \pm 2.3$ & 44 \\
FTLD & Frontal ctx & 9 & $71.6 \pm 3.4$ & $19.3 \pm 4.2$ & 44 \\
C & Frontal ctx & 9 & $82.4 \pm 2.6$ & 56 \\
\hline
\end{tabular}

PMI: postmortem interval, AD: Alzheimer's disease, C: control subjects, and FTLD: frontotemporal lobar degeneration.

Forty $\mu \mathrm{g}$ of total protein from each homogenate was mixed with sample buffer ( $1 \mathrm{x}$ Laemmli buffer, $0.1 \%$ bromophenol blue, and $2.5 \%$ mercaptoethanol) and boiled (five min.) before SDS-PAGE on a $10-20 \%$ Tris-Tricine gel (BioRad). Next, the proteins were transferred (over night) to a nitrocellulose membrane (Bio-Rad) and blocked (1 h.) in TBS with $5 \%$ milk powder (BioRad). After washing in TBS with $0.1 \%$ Tween (TBS-T), the samples were incubated with primary antibody $(1 \mathrm{~h}$.) and washed in TBS-T before incubation with fluorophore-conjugated secondary antibody (30 min.). After washing in TBS-T and TBS, respectively, fluorescence was detected with the Odyssey imaging system (LI-COR/Westburg, Leusden, Netherlands).

In order to adjust for unequal sample loading, the protein levels were calculated as a ratio to GAPDH levels. Therefore, after detection, the membranes were incubated with a primary GAPDH antibody (30 $\mathrm{min}$.). Next, they were washed in TBS-T, followed by incubation with fluorophoreconjugated secondary antibody (30 min.). After washing in TBS-T and TBS, respectively, fluorescence was measured with the Odyssey.

As primary antibodies, C-33 (1:250, Santa Cruz biotechnology, Santa Cruz, CA, USA) was used for detection of MYC, ab60727 (1:500, Abcam, Cambridge, MA, USA) and 6H5-3 (1:500, Upstate, Lake Placid, NY, USA) for TCF7L2 and G9545 (1:10000, Sigma-Aldrich, St. Louise, MO, USA) for GAPDH. As secondary antibodies, IRdye 800CW-conjugated anti-mouse antibody $(1: 5000$, Rockland, Gilbertsville, PA, USA) was used for MYC and TCF7L2 whereas Alexa fluor 680-conjugated anti-rabbit antibody $(1: 5000$, VWR, West Chester, PA, USA) was used for GAPDH. All antibodies were diluted in 50/50 Odyssey buffer/TBS-T $0.2 \%$.

2.6. Immunohistochemistry on Human Brains. Ten $\mu \mathrm{m}$ brain sections from tissue blocks embedded in paraffin from temporal cortex of five of the $\mathrm{AD}$ and four of the control brains were included for immunohistochemistry. The tissues were deparaffinized in xylene for ten minutes and incubated in $\mathrm{H}_{2} \mathrm{O}_{2}$ /methanol for 20 minutes followed by hydration in decreasing concentrations of ethanol and $\mathrm{H}_{2} \mathrm{O}$. Antigen retrieval was performed in citrate buffer (20 minutes, $10 \mathrm{mM}$, $\left.\mathrm{pH} 6.0,95^{\circ} \mathrm{C}\right)$. After a brief wash in PBS, the tissues were blocked in normal goat serum (NGS, 5\%) followed by incubation overnight at $4{ }^{\circ} \mathrm{C}$ with the primary antibody in $1.5 \%$ NGS (mouse anti-c-myc, 1:50, Santa Cruz Biotechnology; anti-TCF7L2 1:500, Millipore, Billerica, MA). Next day, the sections were washed in PBS followed by incubation with the secondary antibody in $1.5 \%$ NGS (biotinylated goat anti-mouse, $1: 200)$. After additional washing in PBS, the Vectastain Elite ABC kit (Vector Labs, Burlingame, CA) and the DAB kit (Vector Labs) were used according to the manufacturer's instructions. Finally, sections were washed in PBS and dehydrated in increasing concentrations of EtOH and xylene before they were mounted with Permount.

\section{Results}

Altogether 530 genes were found to be differentially expressed $(P<.05)$ when comparing mRNA levels between six tg-ArcSwe and six nontransgenic mice. The altered genes were either down- or upregulated, ranging from $88 \%$ to $112 \%$ of the reference levels in nontransgenic mice. Using DAVID, the genes were categorized according to their respective KEGG pathways. Thereby, three pathways emerged as being particularly altered in the tg-ArcSwe mice: the thyroid cancer pathway, the adipocytokine signaling pathway, and the Wnt signaling pathway. Four of the genes with altered expression were previously described to be involved in thyroid cancer development, six of the genes in adipocytokine signaling, and nine of the genes in the Wnt signaling pathway. Of the Wnt-related genes, mRNA levels of TCF7L2, CCND3, MYC, NKD2, and PPP3CB were increased whereas mRNA levels of PLCB1, NFAT5, LEF1, and PPP2R2C were decreased in transgenic as compared to nontransgenic mice (Table 3).

As the Wnt signaling pathway demonstrated the highest number of differentially expressed genes, we focused on this pathway for further analyses. First, we wanted to investigate whether the relatively small changes of the nine Wnt pathway genes could be detected with an independent technique. Therefore, we performed qPCR on cDNA preparations derived from the same RNA samples that were used for microarray analyses. However, after normalization to GAPDH, the small changes between transgenic and nontransgenic mice for the nine Wnt genes could not be verified with this method (Table 3 ).

When examining mRNA levels of the nine Wnt signaling pathway genes in human brains, two of the genes with increased mRNA levels in transgenic brains, TCF7L2 and $M Y C$, displayed significantly increased mRNA levels also in AD brain $(n=13)$ as compared to nondemented control brain $(n=9)$ (both $P<.05)$ (Table 3, Figure 1). Moreover, the mRNA levels of these two genes were found to correlate with each other in the AD samples (Spearman $r=0.896$, $P<.001$ ) (Figure $1(\mathrm{c})$ ). Unlike in transgenic mouse brains, the mRNA levels of the other seven investigated genes did not 
TABLE 3: Fold changes and $P$ values when comparing tg-ArcSwe mice and nontransgenic littermates and when comparing AD patients and control subjects (C).

\begin{tabular}{|c|c|c|c|c|c|c|c|}
\hline \multirow{3}{*}{ Gene } & \multirow{3}{*}{ Protein } & \multicolumn{4}{|c|}{ Tg-ArcSwe versus nontransgenic } & \multirow{2}{*}{\multicolumn{2}{|c|}{$\begin{array}{c}\mathrm{AD} \text { versus } \mathrm{C} \\
\mathrm{qPCR}\end{array}$}} \\
\hline & & \multicolumn{2}{|c|}{ Microarray } & \multicolumn{2}{|l|}{ qPCR } & & \\
\hline & & Fold change & $P$ & Fold change & $P$ & Fold change & $P$ \\
\hline CCND3 & Cyclin D3 & 1.10 & $<.05$ & 0.88 & n.s. & 1.14 & n.s. \\
\hline LEF1 & Lymphoid enhancer-binding factor 1 & 0.92 & $<.05$ & 0.88 & n.s. & 0.90 & n.s. \\
\hline$M Y C$ & V-myc myelocytomatosis viral oncogene homolog & 1.09 & $<.05$ & 0.91 & n.s. & 2.02 & $<.05$ \\
\hline NFAT5 & Nuclear factor of activated T-cells 5 & 0.91 & $<.05$ & 0.96 & n.s. & 1.21 & n.s. \\
\hline NKD2 & Naked cuticle homolog 2 (Drosophila) & 1.08 & $<.05$ & 1.05 & n.s. & 0.92 & n.s. \\
\hline PLCB1 & Phospholipase C, beta 1 & 0.90 & $<.01$ & 0.99 & n.s. & 0.82 & n.s. \\
\hline$P P P 2 R 2 C$ & Protein phosphatase 2 , regulatory subunit $\mathrm{B}$, gamma & 0.93 & $<.05$ & 1.21 & n.s. & 1.24 & n.s. \\
\hline PPР3CB & Protein phosphatase 3 , catalytic subunit & 1.08 & $<.05$ & 1.03 & n.s. & 0.79 & n.s. \\
\hline TCF7L2 & Transcription factor 7-like 2 & 1.10 & $<.05$ & 0.95 & n.s. & 1.43 & $<.05$ \\
\hline
\end{tabular}

n.s.: not significant.
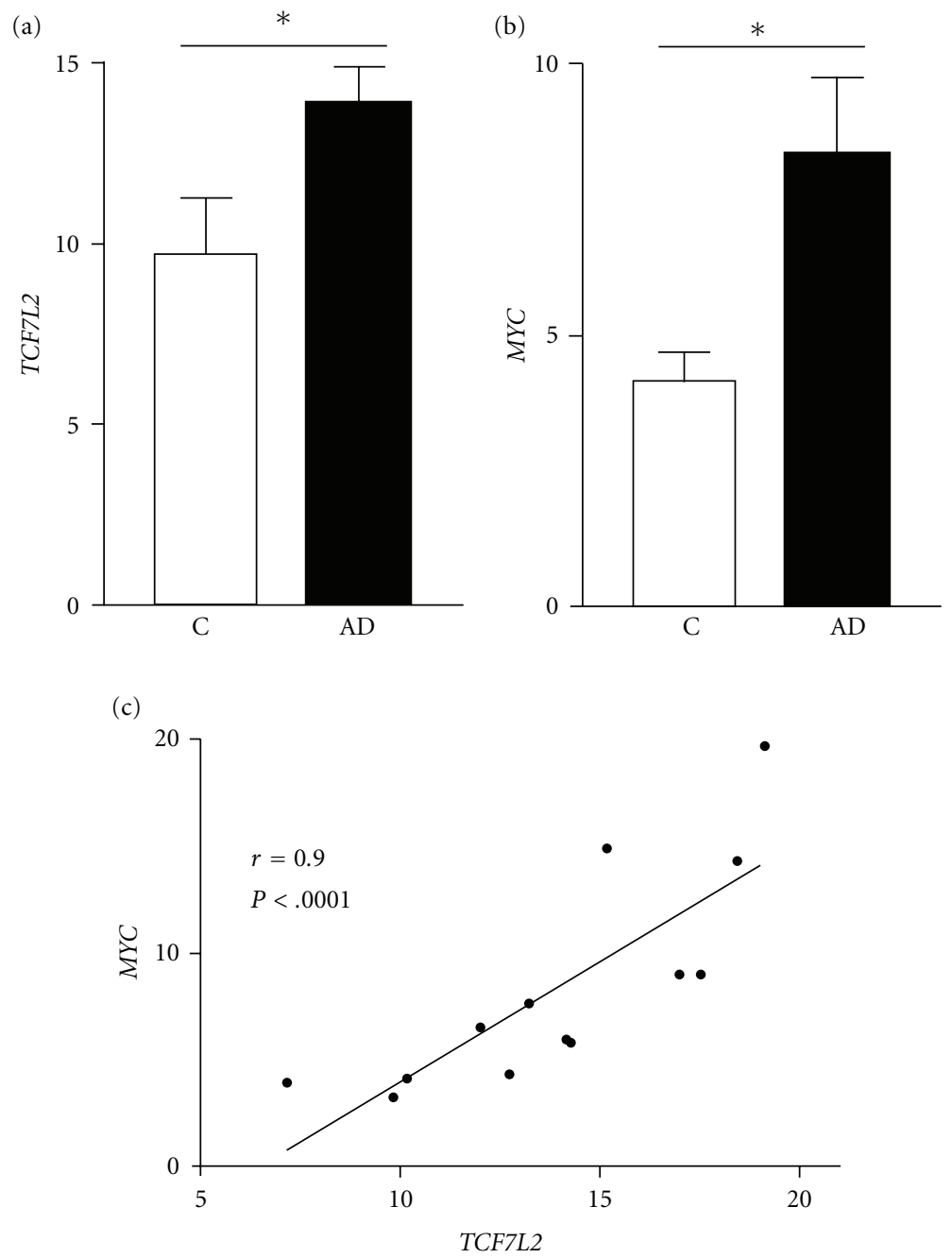

FIGURE 1: Relative mRNA levels of (a) TCF7L2 and (b) MYC in control (C) $(n=9)$ and AD ( $n=13)$ brain as measured by qPCR, normalized to GAPDH and to a calibrator sample (mean \pm SEM, $P<.05$ for both). (c) Correlation of TCF7L2 and MYC in the individual AD brains (Spearman $r=0.9, P<.0001)$. 
show any altered levels in $\mathrm{AD}$ as compared to brains from healthy controls (Table 3).

In order to elucidate whether the observed alterations in mRNA levels of TCF7L2 and MYC were AD-specific features or a result of the neurodegenerative process itself, the two genes were also analyzed in frontal neocortical tissue from a set of cases $(n=9)$ with frontotemporal lobar degeneration (FTLD) and compared to frontal cortex tissue from nondemented controls $(n=9)$. No significant differences were seen, although there was a trend for increased levels of TCF7L2 mRNA in the FTLD group $(P=.08)$ (data not shown).

As the Wnt signaling pathway is known to be upregulated in neurogenesis, we wanted to explore whether the increased mRNA levels of TCF7L2 and MYC reflected neurogenesis in the $\mathrm{AD}$ brains. Thus, mRNA levels of two neurogenesis markers (neural cell adhesion molecule 1NCAM1 [16] doublecortin-DCX [17]) and one marker for neurons that are migrating or undergoing axonal growth (dihydropyrimidinase-like 3-DPYSL3 [18]) were analyzed by qPCR. Only mRNA levels of DPYSL3 were increased in AD brain $(P<.05)$ whereas the NCAM1 and DCX mRNA levels were unchanged as compared to control brains.

To investigate if the observed changes in mRNA levels of TCF7L2 and MYC were paralleled by changes in the corresponding proteins (transcription factor 7-like 2 and $\mathrm{v}$-myc myelocytomatosis viral oncogene homolog), western blot and immunohistochemical analyses were carried out on temporal neocortex from the same $\mathrm{AD}$ and control subjects. For western blot, we used human brain tissue homogenates from the same regions as that used for the mRNA analyses. For transcription factor 7-like 2, no signals could be seen in any of the brains using either of two antibodies. For vmyc myelocytomatosis viral oncogene homolog, clear signals were obtained but no significant change was detected in the $\mathrm{AD}$ cases (not shown). For immunohistochemistry on temporal cortical sections, we obtained signals only from transcription factor 7-like 2 but could not see any differences between $\mathrm{AD}$ and control brains (not shown). For v-myc myelocytomatosis viral oncogene homolog, no signals were seen on immunohistochemistry from any of the tissues investigated (not shown).

\section{Discussion}

The amyloid cascade hypothesis [19] is widely accepted, but it is still unclear which form of $A \beta$ that initiates the disease process or has the most neurotoxic properties. Studies have suggested that soluble $A \beta$ oligomers are particularly toxic $[20]$ and effects on gene expression by such $A \beta$ species should therefore be of particular interest.

For this study, microarray analyses were performed on five-month old tg-ArcSwe mice with marked accumulation of intraneuronal $A \beta$ and increased levels of soluble $A \beta$ protofibrils in the brains [21]. For comparison, age-matched nontransgenic littermates were used. The fold changes in brain levels of various mRNAs from the transgenic mice were surprisingly small, ranging from $88 \%$ to $122 \%$ of that in nontransgenic littermates. These subtle changes could have been due to the fact that very young animals were used, when $\mathrm{A} \beta$ possibly does not yet affect biological pathways to a great extent. The relatively small differences could also have been explained by the fact that whole hemispheres were used for extraction of RNA. If only areas displaying intracellular $A \beta$ had been used, the changes might have been more pronounced. Nevertheless, the genes found to be alternatively expressed in this microarray analysis may represent downstream molecular cascades triggered by the early formation of intracellular $\mathrm{A} \beta$ seen in this mouse model.

Three biochemical pathways - the thyroid cancer pathway, the adipocytokine signaling pathway, and the Wnt signaling pathway-were overrepresented among the genes that had altered mRNA levels in the transgenic mice. Nine genes from the Wnt pathway were found to be upregulated in the mice brain. Although the fold changes were very small and despite that we could not verify the increase for all nine mRNA species by qPCR, we decided to further study the Wnt pathway in postmortem AD brains. We then found that two of the nine investigated genes, TCF7L2 and MYC, had significantly increased mRNA levels also in AD brain. Both genes encode proteins that are part of the Wnt signaling pathway, in which the transcription factor 7-like 2 regulates transcription of the MYC gene [22]. This link in biological activity was also well illustrated by the correlation between the respective mRNA levels demonstrated in this study.

MYC is of particular interest as it has been illustrated on a transgenic mouse model that induction of this protooncogene can drive cell cycle re-entry and result in neuronal cell death, gliosis, and cognitive deficits [23]. Thus, the upregulation of MYC mRNA in human brain could possibly contribute to some of the neurodegenerative features seen in $\mathrm{AD}$.

The observed increase in mRNA levels of TCF7L2 and MYC indicates an increase in Wnt signaling in AD pathogenesis. Accordingly, recent evidence suggests that levels of nuclear calcineurin are increased in post mortem $\mathrm{AD}$ brains [24]. On the contrary, other studies have reported increased levels of GSK3 $\beta$, suggesting a repression of the Wnt signaling pathway in $\mathrm{AD}$ [25]. However, in our study the mRNA levels of both GSK3B and $\beta$-catenin were unchanged, both in tg-ArcSwe mouse brain and in AD brain (data not shown). In addition, the mRNA levels of PPP2R2C were slightly decreased in tg-ArcSwe mouse brain whereas they were nonsignificantly increased in the AD brain (Table 3).

The observed increase in mRNA levels of TCF7L2 and MYC between $\mathrm{AD}$ and control brains was not paralleled by increased levels of the respective proteins (transcription factor 7-like 2 and v-myc myelocytomatosis viral oncogene homolog). The discrepancy between mRNA and protein levels may be explained by a rapid turnover in brain of these signaling molecules.

Several lines of evidence suggest that both cell cycle activation and neurogenesis may be features in neurodegeneration. In the $\mathrm{AD}$ brain, cell cycle re-entry is believed to occur prior to the development of tangles and plaques (reviewed in [26]). Moreover, Wnt signaling has been demonstrated to be the principal regulator of adult hippocampal neurogenesis [27], which has been suggested to occur in the AD brain 
[28]. We therefore reasoned that an upregulation of the Wnt signaling pathway may be explained by an increased neurogenesis in the investigated brains. One of the analyzed genes known to be upregulated in neurogenesis indeed displayed increased mRNA levels in our samples, suggesting that an upregulated Wnt signaling pathway may be related to increased neurogenesis in the $\mathrm{AD}$ brain. On the other hand, mRNA levels of the two other neurogenesis-related genes investigated were not found to be changed in $\mathrm{AD}$, thus making the interpretation more difficult.

Interestingly, TCF7L2 was shown to be associated with type II diabetes [29], and increased levels of TCF7L2 mRNA in human islets have been found in type II diabetes [30]. There are commonalities between $\mathrm{AD}$ and diabetes with both disorders being associated with amyloidogenic deposits, and patients with diabetes have been reported to be more prone to develop $\mathrm{AD}[31]$. Also, soluble $\mathrm{A} \beta$ oligomers may impair insulin signaling in the brain through a reduction in neuronal surface insulin receptors [32]. Therefore, TCF7L2 may represent a molecular link between $\mathrm{AD}$ and diabetes pathogenesis.

In conclusion, we have compared gene expression patterns using microarray analysis of tg-ArcSwe and nontransgenic mice, indicating only subtle changes in mRNA levels in young tg-ArcSwe. Interestingly, we found that the tg-ArcSwe mice displayed altered mRNA levels of several members of the Wnt signaling pathway as compared to nontransgenic mice. Moreover, we have investigated whether differentially expressed genes in this model also had altered mRNA levels in brains from $\mathrm{AD}$ patients. The mRNA levels of two of these genes, TCF7L2 and MYC, were significantly increased also in AD brain $(P<.05)$, whereas their levels were not significantly changed in frontal cortex of FTLD brains as compared to frontal cortex from control brains. Although the number of brains analyzed was limited, these results cautiously suggest that the observed differences may be $\mathrm{AD}$ specific, rather than a general feature of neurodegeneration. Finally, increased mRNA levels of a neuronal plasticity marker suggest that the upregulation of certain Wnt genes may give further support for ongoing neurogenesis in the AD brain.

\section{Acknowledgments}

This work was supported by The Swedish Research Council (2009-4567 (for L. Lannfelt); 2009-4389 (for L. N. G. Nilsson); 2006-6326, and 2006-3464 (for M. Ingelsson)), The Swedish Alzheimer Foundation, The Swedish Dementia Foundation, The Swedish Brain Foundation, The Swedish Society of Medicine, Gun and Bertil Stohne's Foundation, The Freemason Foundation, Åhlén Foundation, Lundströms Minne, and APOPIS (Contract no. LSHM-CT-2003503330). Also, the Uppsala University Transgenic Facility (UUTF) is greatly acknowledged for helping in developing the APP transgenic model.

\section{References}

[1] A. Goate, M. C. Chartier-Harlin, M. Mullan et al., "Segregation of a missense mutation in the amyloid precursor protein gene with familial Alzheimer's disease," Nature, vol. 349, no. 6311, pp. 704-706, 1991.

[2] E. Levy-Lahad, W. Wasco, P. Poorkaj et al., "Candidate gene for the chromosome 1 familial Alzheimer's disease locus," Science, vol. 269, no. 5226, pp. 973-977, 1995.

[3] R. Sherrington, E. I. Rogaev, Y. Liang et al., "Cloning of a gene bearing missense mutations in early-onset familial Alzheimer's disease," Nature, vol. 375, no. 6534, pp. 754-760, 1995.

[4] E. H. Corder, A. M. Saunders, W. J. Strittmatter et al., "Gene dose of apolipoprotein E type 4 allele and the risk of Alzheimer's disease in late onset families," Science, vol. 261, no. 5123, pp. 921-923, 1993.

[5] A. M. Saunders, W. J. Strittmatter, D. Schmechel et al., "Association of apolipoprotein E allele $\varepsilon 4$ with late-onset familial and sporadic Alzheimer's disease," Neurology, vol. 43, no. 8, pp. 1467-1472, 1993.

[6] P. H. Reddy and S. McWeeney, "Mapping cellular transcriptosomes in autopsied Alzheimer's disease subjects and relevant animal models," Neurobiology of Aging, vol. 27, no. 8, pp. 1060-1077, 2006.

[7] D. P. Hanger, K. Hughes, J. R. Woodgett, J. P. Brion, and B. H. Anderton, "Glycogen synthase kinase-3 induces Alzheimer's disease-like phosphorylation of tau: Generation of paired helical filament epitopes and neuronal localisation of the kinase," Neuroscience Letters, vol. 147, no. 1, pp. 58-62, 1992.

[8] D. E. Kang, S. Soriano, M. P. Frosch et al., "Presenilin 1 facilitates the constitutive turnover of $\beta$-catenin: differential activity of Alzheimer's disease-linked PS1 mutants in the $\beta$ catenin-signaling pathway," Journal of Neuroscience, vol. 19, no. 11 , pp. 4229-4237, 1999.

[9] H. Clevers, "Wnt/beta-catenin signaling in development and disease," Cell, vol. 127, no. 3, pp. 469-480, 2006.

[10] C. Stenh, H. Englund, A. Lord et al., "Amyloid- $\beta$ oligomers are inefficiently measured by enzyme-linked immunosorbent assay," Annals of Neurology, vol. 58, no. 1, pp. 147-150, 2005.

[11] A. Lord, H. Kalimo, C. Eckman, X. Q. Zhang, L. Lannfelt, and L. N. G. Nilsson, "The Arctic Alzheimer mutation facilitates early intraneuronal $\mathrm{A} \beta$ aggregation and senile plaque formation in transgenic mice," Neurobiology of Aging, vol. 27, no. 1, pp. 67-77, 2006.

[12] A. Lord, H. Englund, L. Söderberg et al., "Amyloid- $\beta$ protofibril levels correlate with spatial learning in Arctic Alzheimer's disease transgenic mice," FEBS Journal, vol. 276, no. 4, pp. 995-1006, 2009.

[13] G. Dennis Jr., B. T. Sherman, D. A. Hosack et al., "DAVID: database for annotation, visualization, and integrated discovery," Genome Biology, vol. 4, no. 5, p. P3, 2003.

[14] M. Kanehisa and S. Goto, "KEGG: Kyoto encyclopedia of genes and genomes," Nucleic Acids Research, vol. 28, no. 1, pp. 27-30, 2000.

[15] F. Pattyn, P. Robbrecht, A. De Paepe, F. Speleman, and J. Vandesompele, "RTPrimerDB: the real-time PCR primer and probe database, major update 2006," Nucleic Acids Research, vol. 34, pp. D684-D688, 2006.

[16] L. Bonfanti and D. T. Theodosis, "Expression of polysialylated neural cell adhesion molecule by proliferating cells in the subependymal layer of the adult rat, in its rostral extension and in the olfactory bulb," Neuroscience, vol. 62, no. 1, pp. 291-305, 1994.

[17] J. P. Brown, S. Couillard-Després, C. M. Cooper-Kuhn, J. Winkler, L. Aigner, and H. G. Kuhn, "Transient expression of doublecortin during adult neurogenesis," Journal of Comparative Neurology, vol. 467, no. 1, pp. 1-10, 2003. 
[18] J. Nacher, D. R. Rosell, and B. S. McEwen, "Widespread expression of rat collapsin response-mediated protein 4 in the telencephalon and other areas of the adult rat central nervous system," Journal of Comparative Neurology, vol. 424, no. 4, pp. 628-639, 2000.

[19] J. A. Hardy and G. A. Higgins, "Alzheimer's disease: the amyloid cascade hypothesis," Science, vol. 256, no. 5054, pp. 184-185, 1992.

[20] D. M. Walsh, I. Klyubin, J. V. Fadeeva et al., "Naturally secreted oligomers of amyloid $\beta$ protein potently inhibit hippocampal long-term potentiation in vivo," Nature, vol. 416, no. 6880, pp. 535-539, 2002.

[21] H. Englund, D. Sehlin, A. S. Johansson et al., "Sensitive ELISA detection of amyloid- $\beta$ protofibrils in biological samples," Journal of Neurochemistry, vol. 103, no. 1, pp. 334-345, 2007.

[22] T. C. He, A. B. Sparks, C. Rago et al., "Identification of c-MYC as a target of the APC pathway," Science, vol. 281, no. 5382, pp. 1509-1512, 1998.

[23] H. G. Lee, G. Casadesus, A. Nunomura et al., "The neuronal expression of MYC causes a neurodegenerative phenotype in a novel transgenic mouse," American Journal of Pathology, vol. 174, no. 3, pp. 891-897, 2009.

[24] H. Y. Wu, E. Hudry, T. Hashimoto et al., "Amyloid $\beta$ induces the morphological neurodegenerative triad of spine loss, dendritic simplification, and neuritic dystrophies through calcineurin activation," Journal of Neuroscience, vol. 30, no. 7, pp. 2636-2649, 2010.

[25] A. Takashima, K. Noguchi, G. Michel et al., "Exposure of rat hippocampal neurons to amyloid $\beta$ peptide (25-35) induces the inactivation of phosphatidyl inositol-3 kinase and the activation of tau protein kinase I/glycogen synthase kinase3ß," Neuroscience Letters, vol. 203, no. 1, pp. 33-36, 1996.

[26] H. G. Lee, G. Casadesus, X. Zhu et al., "Cell cycle reentry mediated neurodegeneration and its treatment role in the pathogenesis of Alzheimer's disease," Neurochemistry International, vol. 54, no. 2, pp. 84-88, 2009.

[27] D. C. Lie, S. A. Colamarino, H. J. Song et al., "Wnt signalling regulates adult hippocampal neurogenesis," Nature, vol. 437, no. 7063, pp. 1370-1375, 2005.

[28] K. Jin, A. L. Peel, X. O. Mao et al., "Increased hippocampal neurogenesis in Alzheimer's disease," Proceedings of the National Academy of Sciences of the United States of America, vol. 101, no. 1, pp. 343-347, 2004.

[29] S. F. A. Grant, G. Thorleifsson, I. Reynisdottir et al., "Variant of transcription factor 7-like 2 (TCF7L2) gene confers risk of type 2 diabetes," Nature Genetics, vol. 38, no. 3, pp. 320-323, 2006.

[30] V. Lyssenko, R. Lupi, P. Marchetti et al., "Mechanisms by which common variants in the TCF7L2 gene increase risk of type 2 diabetes," Journal of Clinical Investigation, vol. 117, no. 8, pp. 2155-2163, 2007.

[31] A. Ott, R. P. Stolk, A. Hofman, F. Van Harskamp, D. E. Grobbee, and M. M. B. Breteler, "Association of diabetes mellitus and dementia: the Rotterdam study," Diabetologia, vol. 39, no. 11, pp. 1392-1397, 1996.

[32] W. Q. Zhao, F. G. De Felice, S. Fernandez et al., "Amyloid beta oligomers induce impairment of neuronal insulin receptors," FASEB Journal, vol. 22, no. 1, pp. 246-260, 2008. 


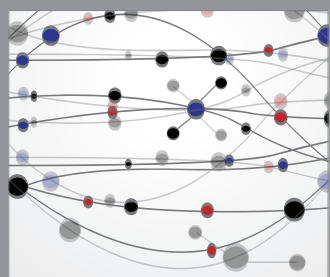

The Scientific World Journal
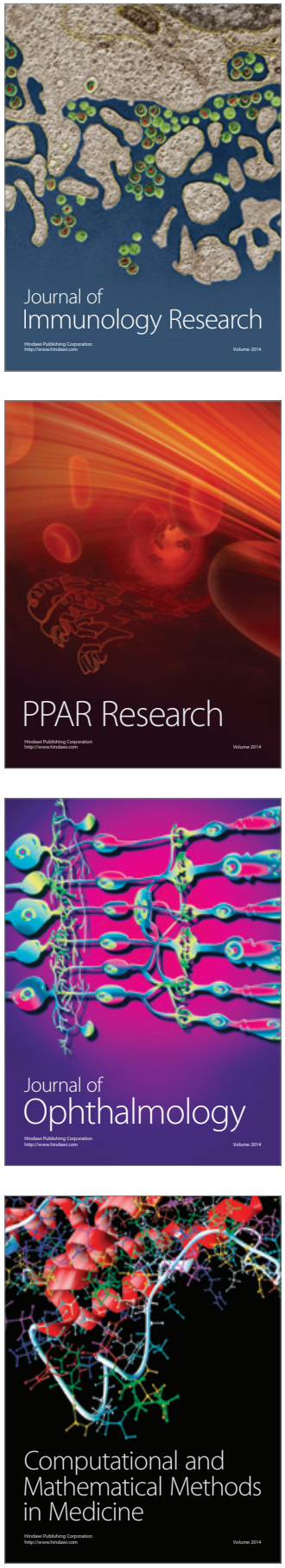

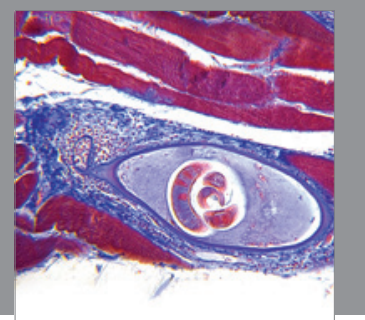

Gastroenterology

Research and Practice
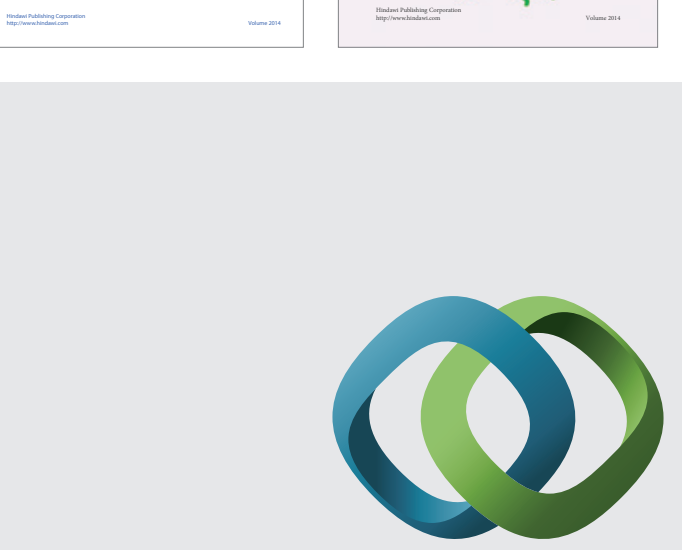

\section{Hindawi}

Submit your manuscripts at

http://www.hindawi.com
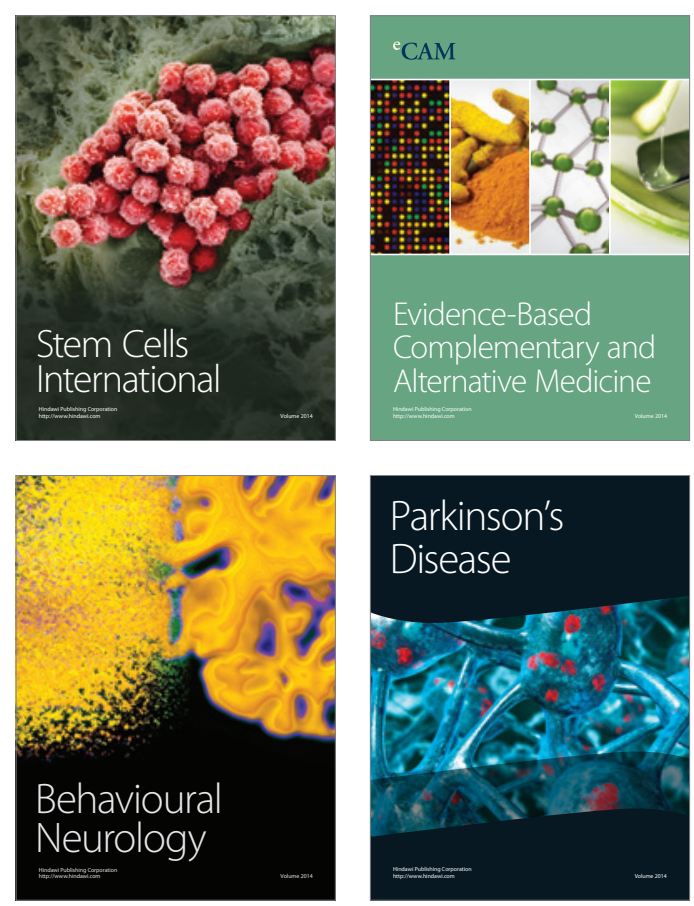

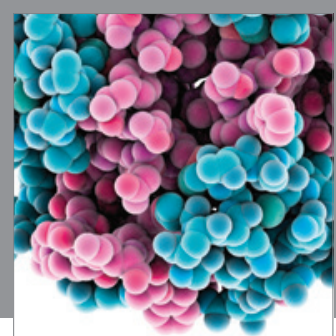

Journal of
Diabetes Research

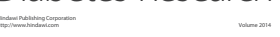

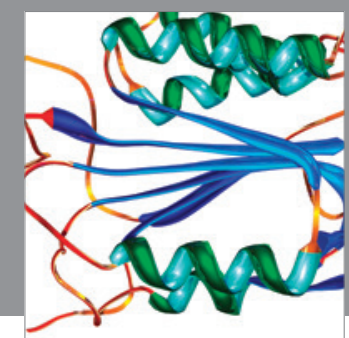

Disease Markers
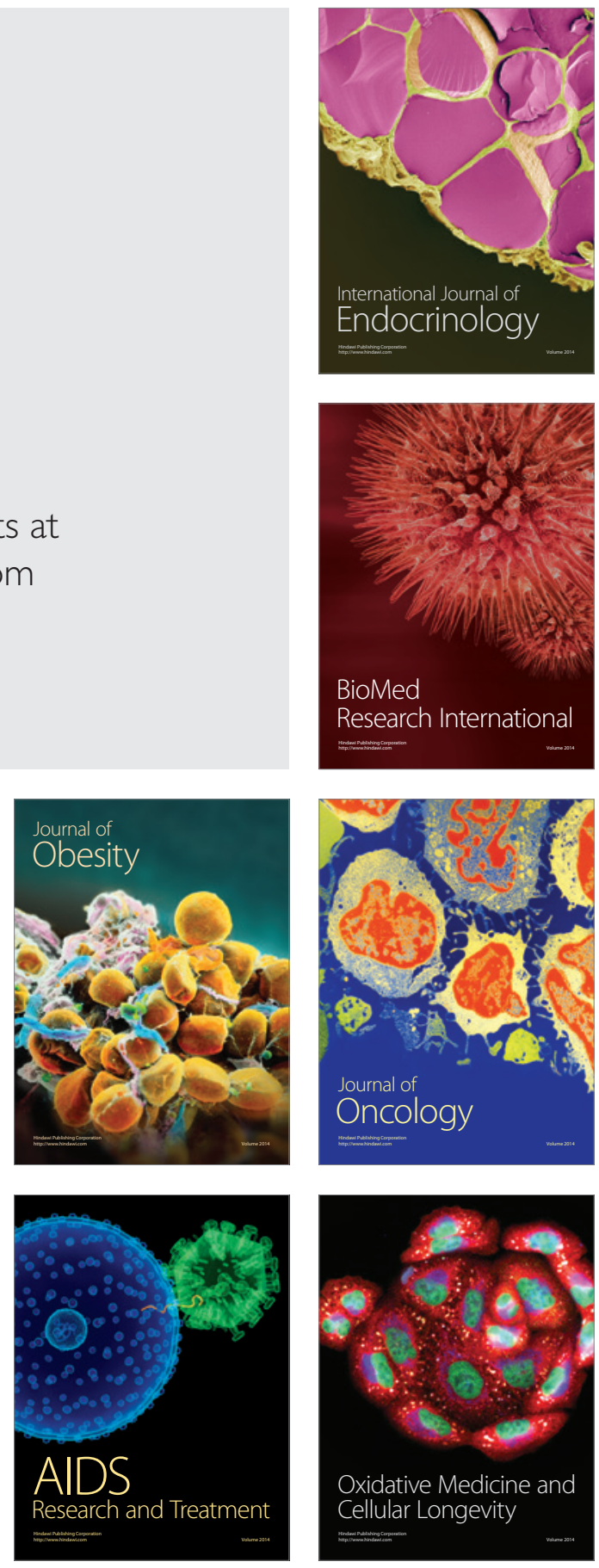